\title{
Critical features and some properties polymer compositions containing high-dispersal hexanitrohexaazaizowurcitan
}

\author{
(C) Vladimir N. Popok, ${ }^{*+}$ and Nikolay I. Popok \\ Altai Federal Research and Production Center. Socialist St., 1. Biysk, 659322. Altai Region. Russia. \\ Phone: +7 (3854) 30-19-37. E-mail:vnpopok@mail.ru
}

\begin{abstract}
*Supervising author; ${ }^{+}$Corresponding author
Keywords: hexanitrohexaazaizowurcitan, mixed energy materials, degree of filling, dispersivity, percolation cluster, combustion speed, physical and mechanical parameters, explosive characteristics, invariate dependence.
\end{abstract}

\section{Abstract}

The use of hexanitrohexaazaizowurcitan can in mixed energy compositions based on various polymer binders faces a number of problems caused by the specific properties of this component: resistance under normal conditions most polymorphic modifications of the crystalline product, the difficulty of obtaining a crystalline product of the required dispersal and polymorphic modification, re-crystalization and remodification of the product in polymer mixtures compositions, increased ability to form crystals with most traditional components of energy compositions. Relatively low and selective, in comparison, for example, with compositions based on octogen, the increase in energy efficiency when using hexanitrohexaazaizowurcitan in energy compositions with polymer binders of different nature, puts forward the task of simultaneously addressing the issues of reducing energy losses when burning energy compositions in energy installations of various purposes. The solution of these issues is associated with the use of high-dispersal and nanoscale fillers in the compositions of mixed energy materials.

For the use of hexanitrohexaazaizowurcitan in compositions, along with the problem of choosing a polymer binder, solving the issues of obtaining a crystal product required modification and different variance, including nanoscale, experimental research is needed: critical characteristics of filling polymer compositions (maximum degree of filling; filling corresponding to percolation transitions), their effect on basic properties energy compositions - characteristics of combustion, physical-mechanical and explosive characteristics, physical and chemical stability of properties, etc.; to assess the prospects of using alternative compositions based on the co-crystalyzates of hexanitrohexaazaizowurcitan with other components of mixed compositions.

Taking into account the above and in the development of earlier works, the article provides some results of the definition of critical volume - maximum and critical for the formation of percolatin cluster - degrees of filling polymer compositions with inert hexanitrohexaazaizowurcitan powders of varying variances, including high-dispersal and nanoscale. In addition, data on the relationship of critical characteristics with the characteristics of combustion, physical-mechanical, rheological characteristics of compositions are presented. Data on the effect of high-dispersal and nanoscale powders of hexanitrohexaazaizowurcitan on shock-wave sensitivity of samples of mixed energy materials are presented. The results of tests of alternative homogeneous energy compositions based on the co-crystalyzates of hexanitrohexaazaizowurcitan with a brief analysis of the prospects of their use are also presented.

\section{References}

[1] R.L. Hatch. High Performance Castable CL-20 Explosive. IM/EM Technical Symposium. San Francisco. November 15-17, 2004.

[2] V. Komarov, G. Sakovich, N. Popok, N. Kozyrev. Detonation propagation along percolating cluster in composite explosives. MATEC WEB of Conferences. 243, 00027(2018)//https:/ doi/org/10.1051/matecconf/201824300027.

[3] D.B. Lempert, G.N. Nechiporenko, G.B. Manelis. Energetic Characteristics of Solid Composite Propellants and Ways of Energy Increasing. Central European Journal of Energetic Materials. 2006. Vol.3. No.4. P.73-87.

[4] D.B. Lempert, N.V. Chukanov. The Outlook for the Use of Pseudopolymorphic Solvates in Energetic Materials. Central European Journal of Energetic Materials. 2014. Vol.11. No.2. P.285-294. 
CRITICAL FEATURES AND SOME PROPERTIES POLYMER COMPOSITIONS CONTAINING...

[5] Popok V.N., Khmelev V.N. Mixed Condensed Chemical Fuels based on ammonium nitrate. Principles of layout and properties. Biysk: Ed-vo Alt. State. Tenh. Un-ta. 2014. 222c. (russian)

[6] D.B. Lempert, G.P. Dolganova, H.N. Nechiporenko, L.N. Stesik. Dependence of Optimized Formulations Specific Impulse upon Nature of Metal and Oxidizer. Chem. Phys. (Russ.). 1997. Vol.16. No.9. P.91-100.

[7] G. Lengelle, J. Duterque, J.F. Trubert. Combustion of Solid Propellants. Report. 2004. http://dtic.mil/cgibin/GetTRDoc?AD=ADA425264

[8] V.N. Popok, N.I. Popok. Percolation in mixed energy materials. Characteristics of burning, ignition and sensitivity of mixtures to mechanical stress. Butlerov Communications. 2014. Vol.39. No.8. P.1-16. ROI: jbc-02/14-39-8-1

[9] S. Gallier. Heterogeneous solid propellants: from microstructure to macroscale properties. Progress in Propulsion Physics. 2011. No.2. P.21-34.

[10] S.A. Rashkovsky The role of the structure of heterogeneous condensed systems in the formation of agglomerates. Physics of Combustion and Explosion. 2002. Vol.38. No.4. P.65-76. (russian)

[11] V. N. Popok. Effect of structural factors on burning parameters of mixed energy materials. Butlerov Communications. 2012. Vol.32. No.13. P.75-87. ROI: jbc-01/12-32-13-75

[12] V.N. Popok, N.I. Popok. Features of some methods of obtaining ultra-and nanodisperse powders hexanitrohexaazaisowurtzitane, explosive properties of powders and compositions on their basis. Butlerov Communications. 2018. Vol.55. No.9. P.58-66. DOI: 10.37952/ROI-jbc-01/18-55-9-58

[13] V.N. Popok. Research on hexanitrohexaazaisowurtzitane/polymer co-crystallizate properties. Butlerov Communications. 2012. Vol.30. No.6. P.132-143. ROI: jbc-02/12-30-6-132

[14] V.N. Popok, and N.V. Bychin. Properties thermoreversible cocrystals with a low temperature of melting on a basis hexanitrohexaazaisowurtzitane. Butlerov Communications. 2014. Vol.37. No.2. P.39-52. ROI: jbc-02/14-37-2-39

[15] Zhou Shuiping, A. Pang, G. Tang. Crystal Transition Behaviors of CL-20 in Polyether Solid Propellants Plasticized by Nitrate Esters with co-Existence of HMX and CL-20. New Journal of Chemistry. 2017. P.32. DOI: 10.1039/C7NJ03309E.

[16] V.N. Popok, V.I. Desyatykh, and N.I. Popok. Influence of processes of a cocristallization on rheological and mechanical characteristics of mixes on the basis of hexanitrohexaazaisowurtzitane (HNIW).

Butlerov Communications. 2013. Vol.35. No.9. P.144-155. ROI: jbc-02/13-35-9-144

[17] V.N. Popok, N.V. Bichin, P.I. Taronov. Features of thermal decomposition and thermal explosion of compositions with polycrystals of polyethylene glycol, cyclic nitrates and oxidizing agents. Butlerov Communications. 2018. Vol.56. No.12. P.60-70. DOI: 10.37952/ROI-jbc-01/18-56-12-60

[18] V.N. Popok, N.V. Bichin, and A.A. Averin. Features of interaction of a 2,4-dinitro-2,4-diazapentane and 1,3,5,7-tetranitro-1,3,5,7-tetraazacyclooctane at production and storage the compositions. Butlerov Communications. 2016. Vol.46. No.4. P.1-14. DOI: 10.37952/ROI-jbc-01/16-46-4-1

[19] V. Stepanov, R.B. Patel, R. Mudryy, H. Qiu. Investigation of Nitramine-Based Amorphous Energetics. Propellants, Explosives, Pyrotechnics. 2016. Vol.41. P.142-147.

[20] V.N. Popok, N.I. Popok, N.V. Bychin, and S.N. Crystallization and co-crystallization of CL-20. Aponyakina. Influence of some process conditions on product properties. Butlerov Communications. 2019. Vol.59. No.9. P.1-17. DOI: 10.37952/ROI-jbc-01/19-59-9-1

[21] V.N. Popok, Y.A. Pivovarov, and N.I. Popok. Polymeric binding, containing hexanitrohexaazaisowurtzitane. Butlerov Communications. 2016. Vol.48. No.12. P.102-108. DOI: 10.37952/ROI-jbc-01/1648-12-102

[22] L.V. Ravichev, A.V. Bespalov, V.Y. Loginov. Calculating the viscosity of suspensions of catalyst and polymer masses. Chemical industry. 2002. No.5. P.1-6. (russian)

[23] V.N. Popok. Dispersions characteristics burning of composite power materials. Influence of a structural factor. Butlerov Communications. 2017. Vol.49. No.2. P.122-129. DOI: 10.37952/ROI-jbc-01/17-49-2-122

[24] H. Scher, R. Zallen. Critical density in percolation processes. J. Chem. Phys. 1970. Vol.53. No.9. P.3759-3761.

[25] V.N. Popok. Correlation of physical-mechanical characteristics composition power materials. Butlerov Communications. 2017. Vol.49. No.3. P.135-146. DOI: 10.37952/ROI-jbc-01/17-49-3-135

[26] K.V.S. Babu, P.K. Raju, C.R. Thomas, A.S. Hamed, K.N. Ninan. Studies on composite solid propellant with tri-modal ammonium perchlorate containing an ultrafine fraction. Defence Technology. 2017. Vol.13. P.239-245.

[27] V.N. Popok, N.I. Popok, and Y A. Pivovarov. Influence of dispersion and polymorphic modification on explosive characteristics, thermal decomposition and combustion of CL-20 and composite power materials on its basis. Butlerov Communications. 2017. Vol.49. No.3. P.147-155. DOI: 10.37952/ROIjbc-01/17-49-3-147 
[28] B. Huang, M. Cao, F. Nie, etc. Construction and Properties of Structure and Size-controlled Micro/nano-Energetic Materials. Defence Technology. 2013. No.9. P.59-79. 